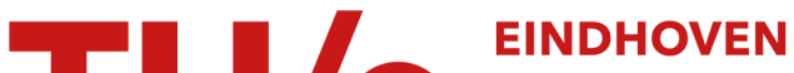 \\ UNIVERSITY OF \\ TECHNOLOGY
}

\section{Modeling of flux switching permanent magnet machines with Fourier Analysis}

Citation for published version (APA):

Gysen, B. L. J., Ilhan, E., Meessen, K. J., Paulides, J. J. H., \& Lomonova, E. (2010). Modeling of flux switching permanent magnet machines with Fourier Analysis. IEEE Transactions on Magnetics, 46(6), 1499-1502.

https://doi.org/10.1109/TMAG.2009.2039921

DOI:

10.1109/TMAG.2009.2039921

Document status and date:

Published: 01/01/2010

Document Version:

Publisher's PDF, also known as Version of Record (includes final page, issue and volume numbers)

Please check the document version of this publication:

- A submitted manuscript is the version of the article upon submission and before peer-review. There can be important differences between the submitted version and the official published version of record. People interested in the research are advised to contact the author for the final version of the publication, or visit the $\mathrm{DOI}$ to the publisher's website.

- The final author version and the galley proof are versions of the publication after peer review.

- The final published version features the final layout of the paper including the volume, issue and page numbers.

Link to publication

\section{General rights}

Copyright and moral rights for the publications made accessible in the public portal are retained by the authors and/or other copyright owners and it is a condition of accessing publications that users recognise and abide by the legal requirements associated with these rights.

- Users may download and print one copy of any publication from the public portal for the purpose of private study or research.

- You may not further distribute the material or use it for any profit-making activity or commercial gain

- You may freely distribute the URL identifying the publication in the public portal.

If the publication is distributed under the terms of Article $25 \mathrm{fa}$ of the Dutch Copyright Act, indicated by the "Taverne" license above, please follow below link for the End User Agreement:

www.tue.nl/taverne

Take down policy

If you believe that this document breaches copyright please contact us at:

openaccess@tue.nl

providing details and we will investigate your claim. 


\title{
Modeling of Flux Switching Permanent Magnet Machines With Fourier Analysis
}

\author{
Bart L. J. Gysen, Esin Ilhan, Koen J. Meessen, Johannes J. H. Paulides, and Elena A. Lomonova
}

Department of Electrical Engineering, Eindhoven University of Technology, Eindhoven 5600 MB, The Netherlands

\begin{abstract}
For applications demanding a high torque density and high speed capability, the flux switching permanent magnet machine is an excellent candidate. However, the double salient structure and nonlinear behavior increases the challenge to model the magnetic field distribution and torque output. To date, only the magnetic equivalent circuit (MEC) is employed to model the magnetic field in an analytical manner. However, the MEC method suffers from a coarse discretization and the need for a relative complex adjustment when rotor movement or a parametric sweep is considered. Therefore this paper discusses an alternative technique based on the harmonic or Fourier model which solves these difficulties.
\end{abstract}

Index Terms-Boundary value problem, flux switching, Fourier analysis, permanent magnet machine.

\section{INTRODUCTION}

$\mathbf{T}$ HERE is an increasing demand for electromechanical machines with a high toque density together with high and variable speed capability in, for example, the automotive industry [1]. The flux switching permanent magnet (FSPM) machine is a good candidate since it combines the advantages of a switched reluctance machine (high speed and robust rotor structure) and a brushless permanent magnet machine (high torque density) [2]. This combination is achieved by placing the permanent magnets on the stator side, see Fig. 1, together with the three phase windings, hereby pre-biasing the magnetic field in the soft-magnetic material. This leads to an increased variation in the magnetic energy, resulting in a higher torque density. Furthermore, since the permanent magnets are placed on the stator side, very high speeds can be reached and the rotor is robust and suitable to work in harsh environments.

Due to the nonlinear behavior and double salient structure, modeling, and analysis becomes difficult and it is in the literature particularly done with finite-element analysis (FEA) [3] or with the magnetic equivalent circuit (MEC) model [2]. The FEA has the disadvantage of a long computational time whereas the MEC model suffers from coarse discretization of the resulting field solution, leading to inaccurate prediction of the output torque. Furthermore, the MEC model is dependent on the definition of flux paths which changes during rotation of the machine or varying the geometrical parameters. Therefore, the total MEC model consists of a combination of different MEC models [2]. This indicates the necessity of investigating alternative modeling tools in order to analyze the behavior of this machine. Therefore, this paper deals with an alternative modeling technique by means of Fourier analysis [4], [5], which solves the disadvantages of the MEC model. Although one of the main assumptions in this modeling technique is that the iron is infinitely

Manuscript received October 29, 2009; revised December 22, 2009; accepted December 29, 2009. Current version published May 19, 2010. Corresponding author: B. L. J. Gysen (e-mail: b.l.j.gysen@tue.nl).

Color versions of one or more of the figures in this paper are available online at http://ieeexplore.ieee.org.

Digital Object Identifier 10.1109/TMAG.2009.2039921

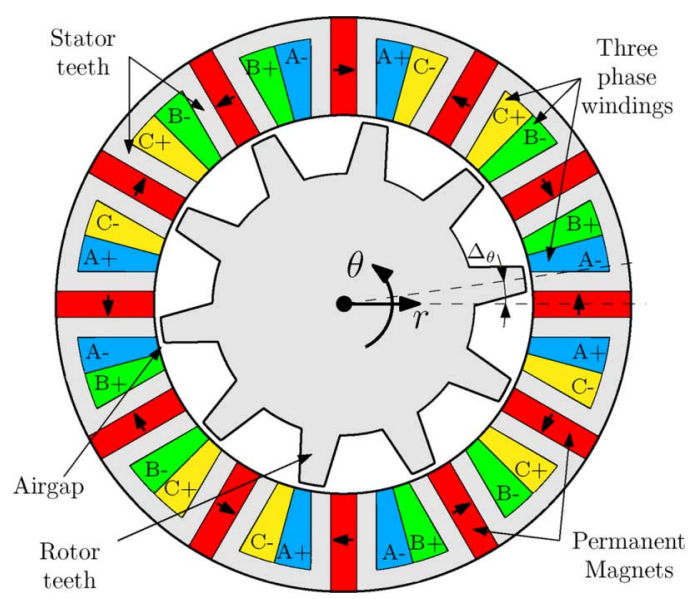

Fig. 1. Flux switching permanent magnet machine.

permeable, it still allows for investigation of various topologies, characteristic behavior and parameter sweep. Furthermore, this model could be suitable as a coarse model in a space-mapping optimization routine [6].

\section{ASSUMPTIONS}

The main assumption of the analytical model is that the permeability of the soft-magnetic material is considered to be infinite and only a Neumann boundary condition (tangential magnetic field is zero) is applied at the boundary of the soft-magnetic material. The permanent magnets are considered to have a linear second quadrant characteristic with remanence $B_{\text {rem }}$ and relative permeability $\mu_{r}$. The first geometrical assumption is the neglection of the finite axial length, hence the end effects are excluded and only the 2-D polar coordinate system $(r, \theta)$ is used. An FSPM with 10 rotor teeth and 12 stator segments is considered, hence the machine inhibits $180^{\circ}$ periodicity and only half of the machine has to be modeled. Half of the geometry is divided into several regions, $k$. Every region is defined by their angular width $\tau$ and radial height $h$. As a result, the sides of every region should be in radial or angular direction. Therefore the geometry should be adjusted as indicated in Fig. 2. In order to correctly predict the cogging torque, the width of the teeth are kept equal at the airgap side. This changes the effective magnet and coil area, hence the current density and remanent flux density are adjusted in order to obtain equal magnetic and electrical 


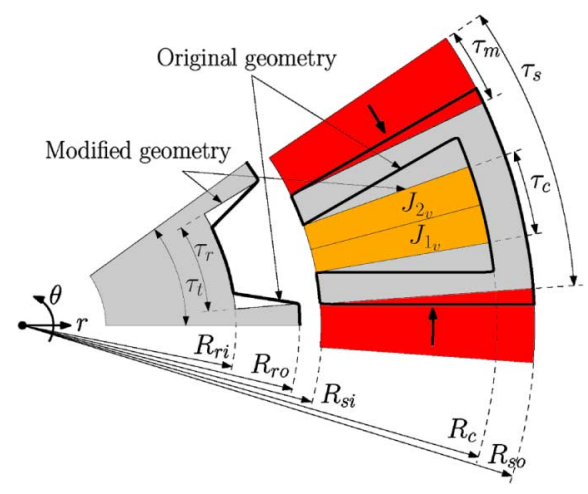

Fig. 2. Modified geometry with parameters.

loading. Since the soft-magnetic material is not considered, the various regions can be distinguished as follows:

- five rotor slot opening regions $\left(k=\mathrm{I}_{v}\right.$ for index $v=$ 0..4);

- $\quad$ one airgap region $(k=\mathrm{II})$;

- six permanent magnet regions $\left(k=\mathrm{III}_{v}\right.$ for index $v=$ $0 \ldots 5$ );

- $\operatorname{six}$ coil regions $\left(k=\mathrm{IV}_{v}\right.$ for index $\left.v=0 \ldots 5\right)$;

- one surrounding air region $(k=\mathrm{V})$.

Furthermore, every region $k$ is considered to have its own local coordinate system $\left(r, \theta_{k}\right)$, where $\theta_{k}$ is given by

$$
\begin{aligned}
& \theta_{k}=\theta-\Delta_{k}-\Delta_{\theta} \text { for regions } \mathrm{I}_{v} \\
& \theta_{k}=\theta-\Delta_{k} \quad \text { for regions II, } \mathrm{III}_{v}, \mathrm{IV}_{v} \text { and } \mathrm{V}
\end{aligned}
$$

where $\Delta_{k}$ is the offset of region $k$ in the $\theta$-direction and $\Delta_{\theta}$ is the rotor displacement, Fig. 1.

\section{FIELD SOLUTION}

\section{A. Source Terms}

The magnetization vector of the permanent magnet regions can be described as

$$
\vec{M}_{0_{\mathrm{III} v}}=(-1)^{v} \frac{B_{\mathrm{rem}}}{\mu_{0}} \vec{e}_{\theta} .
$$

The current density vector in the stator slot opening can be described using Fourier series as

$$
\begin{aligned}
\vec{J}_{\mathrm{IV}_{v}} & =\left[J_{0_{v}}+\sum_{m=1}^{\infty} J_{c_{v}} \cos \left(w_{\mathrm{IV}} \theta_{k}\right)\right] \vec{e}_{z} \\
J_{0_{v}} & =\frac{J_{1_{v}}+J_{2_{v}}}{2} \\
J_{c_{v}} & =\left(J_{2_{v}}-J_{1_{v}}+2 J_{1_{v}} \cos \left(\frac{m \pi}{2}\right)\right) \times \frac{2(-1)^{m} \sin \left(\frac{m \pi}{2}\right)}{m \pi}
\end{aligned}
$$

with $J_{1 v}$ and $J_{2 v}$ the current densities of the corresponding coil region $\mathrm{IV}_{v}$ (see Fig. 2) and $w_{\mathrm{IV}}=m \pi / \tau_{c}$.

\section{B. Flux Density Solution}

For every region, the magnetic field equations are written in terms of the magnetic vector potential $(\vec{B}=\nabla \times \vec{A})$ leading to the Poisson equation

$$
\nabla^{2} \vec{A}=-\mu_{0}\left(\nabla \times \vec{M}_{0}+\vec{J}\right) .
$$

The differential equation is solved using separation of variables and the flux density of region $k$ can be written as

$$
\begin{aligned}
\vec{B}_{k} & =B_{r_{k}}(r, \theta) \vec{e}_{r}+B_{\theta_{k}}(r, \theta) \vec{e}_{\theta} \\
B_{r_{k}} & =\sum_{n=1}^{\infty}\left(B_{r s_{k}} \sin \left(w_{k} \theta_{k}\right)+B_{r c_{k}} \cos \left(w_{k} \theta_{k}\right)\right) \\
B_{\theta_{k}} & =\sum_{n=1}^{\infty}\left(B_{\theta s_{k}} \sin \left(w_{k} \theta_{k}\right)+B_{\theta c_{k}} \cos \left(w_{k} \theta_{k}\right)\right)+B_{0_{k}}
\end{aligned}
$$

note that for regions $\mathrm{I}_{v}, \mathrm{III}_{v}$, and $\mathrm{IV}_{v} m$ is used instead of $n$. The spatial frequencies $w_{k}$ for every region are given by

$$
w_{\mathrm{I}}=\frac{m \pi}{\tau_{r}}, w_{\mathrm{IV}}=\frac{m \pi}{\tau_{c}}, w_{\mathrm{V}}=2 n, w_{\mathrm{II}}=2 n, w_{\mathrm{III}}=\frac{m \pi}{\tau_{m}} .
$$

The functions dependent on the radial direction vary with the considered region. For the rotor slot opening regions $\left(k=\mathrm{I}_{v}\right)$ the functions are given by

$$
\begin{aligned}
& B_{r s_{\mathrm{I} v}}(r, m)=a_{m_{\mathrm{I} v}} r^{w_{\mathrm{I}}-1}+b_{m_{\mathrm{I} v}} r^{-w_{\mathrm{I}}-1} \\
& B_{\theta c_{\mathrm{I} v}}(r, m)=a_{m_{\mathrm{I} v}} r^{w_{\mathrm{I}}-1}-b_{m_{\mathrm{I} v}} r^{-w_{\mathrm{I}}-1}
\end{aligned}
$$

$B_{r c_{\mathrm{I} v}}, B_{\theta s_{\mathrm{I} v}}$, and $B_{0_{\mathrm{I} v}}$ are zero since the tangential field at the sides of the region is zero. For the airgap region $(k=\mathrm{II})$ the functions are given by

$$
\begin{aligned}
& B_{r s_{\mathrm{II}}}(r, n)=a_{n_{\mathrm{II}}} r^{w_{\mathrm{II}}-1}+b_{n_{\mathrm{II}}} r^{-w_{\mathrm{II}}-1} \\
& B_{r c_{\mathrm{II}}}(r, n)=-c_{n_{\mathrm{II}}} r^{w_{\mathrm{II}}-1}-d_{n_{\mathrm{II}}} r^{-w_{\mathrm{II}}-1} \\
& B_{\theta s_{\mathrm{II}}}(r, n)=c_{n_{\mathrm{II}}} r^{w_{\mathrm{II}}-1}-d_{n_{\mathrm{II}}} r^{-w_{\mathrm{II}}-1} \\
& B_{\theta c_{\mathrm{II}}}(r, n)=a_{n_{\mathrm{II}}} r^{w_{\mathrm{II}}-1}-b_{n_{\mathrm{II}}} r^{-w_{\mathrm{II}}-1}
\end{aligned}
$$

and $B_{0_{\mathrm{II}}}$ is zero. The functions for the permanent magnet regions $\left(k=\mathrm{III}_{v}\right)$ are given by

$$
\begin{aligned}
B_{r s_{\mathrm{III} v}}(r, m) & =a_{m_{\mathrm{III} v}} r^{w_{\mathrm{III}-1}}+b_{m_{\mathrm{III} v}} r^{-w_{\mathrm{III}}-1} \\
B_{\theta c_{\mathrm{III} v}}(r, m) & =a_{m_{\mathrm{III} v}} r^{w_{\mathrm{III}-1}-b_{m_{\mathrm{III} v}} r^{-w_{\mathrm{III}-1}}} \\
B_{0_{\mathrm{III} v}}(r) & =(-1)^{v} B_{\mathrm{rem}}-\frac{A_{\mathrm{O}_{\mathrm{III} v}}}{r}
\end{aligned}
$$

$B_{r c_{\mathrm{III} v}}$ and $B_{\theta s_{\mathrm{III} v}}$ are zero for the same reason as for the slot openings. In the coil regions $\left(k=\mathrm{IV}_{v}\right)$, the functions are

$$
\begin{aligned}
B_{r s_{\mathrm{IV} v}}(r, m) & =a_{m_{\mathrm{IV} v}} r^{w_{\mathrm{IV}}-1}+b_{m_{\mathrm{IV} v}} r^{-w_{\mathrm{IV}}-1}+\frac{\mu_{0} w_{\mathrm{IV}} J_{c_{v}} r}{w_{\mathrm{IV}}^{2}-4} \\
B_{\theta c_{\mathrm{IV} v}}(r, m) & =a_{m_{\mathrm{IV} v}} r^{w_{\mathrm{IV}}-1}-b_{m_{\mathrm{IV} v}} r^{-w_{\mathrm{IV}}-1}+\frac{\mu_{0} 2 J_{c_{v}} r}{w_{\mathrm{IV}}^{2}-4} \\
B_{0_{\mathrm{IV} v}}(r) & =\frac{1}{2} \mu_{0} J_{0_{v}}\left(r-\frac{R_{c}^{2}}{r}\right)
\end{aligned}
$$

again $B_{r c_{\mathrm{IV} v}}$ and $B_{\theta s_{\mathrm{IV} v}}$ are zero for the same reason as for the slot openings. Finally, the functions for the surrounding air region $(k=\mathrm{V})$ are described as

$$
\begin{aligned}
& B_{r s_{\mathrm{V}}}(r, n)=b_{n_{\mathrm{V}}} r^{-w_{\mathrm{V}}-1} \\
& B_{r c_{\mathrm{V}}}(r, n)=-d_{n_{\mathrm{V}}} r^{-w_{\mathrm{V}}-1} \\
& B_{\theta s_{\mathrm{V}}}(r, n)=-d_{n_{\mathrm{V}}} r^{-w_{\mathrm{V}}-1} \\
& B_{\theta c_{\mathrm{V}}}(r, n)=-b_{n_{\mathrm{V}}} r^{-w_{\mathrm{V}}-1}
\end{aligned}
$$




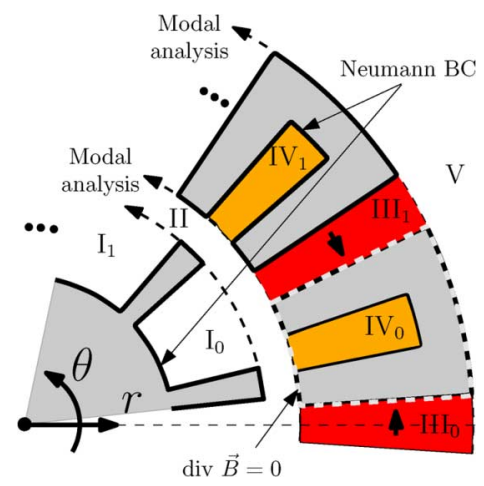

Fig. 3. Division in regions and applied boundary conditions.

and $B_{0 \mathrm{v}}$ is zero.

\section{BOUNDARY CONDITIONS}

In order to solve for the various unknown coefficients of the flux density solution, a set of boundary conditions need to be solved as indicated in Fig. 3. The magnetic field strength should be zero at the inner radius of the rotor and outer radius of the stator slots, hence

$$
B_{\theta c_{\mathrm{I} v}}=\left.0\right|_{r=R_{r i}}, \quad B_{\theta c_{\mathrm{IV} v}}=\left.0\right|_{r=R_{c}} .
$$

The boundary conditions at the outer radius of the rotor and inner and outer radius of the stator are obtained by means of modal analysis, as for example discussed in [5]. The normal magnetic field between the rotor slots and the airgap should be continuous

$$
B_{r s_{\mathrm{I} v}}=\left.\sum_{n=1}^{\infty}\left(B_{r s_{\mathrm{II}}} \varepsilon_{s}\left(\mathrm{I}_{v}\right)+B_{r c_{\mathrm{II}}} \varepsilon_{c}\left(\mathrm{I}_{v}\right)\right)\right|_{r=R_{r o}}
$$

where the correlation functions $\varepsilon_{s}$ and $\varepsilon_{c}$ are given in the Appendix. The tangential magnetic field between the rotor slots and the airgap should be continuous and zero at the rotor teeth

$$
\begin{aligned}
& B_{\theta s_{\mathrm{II}}}=\left.\sum_{v=0}^{4} \sum_{m=1}^{\infty} B_{\theta c_{\mathrm{I} v}} \kappa_{c}\left(\mathrm{I}_{v}\right)\right|_{r=R_{r o}} \\
& B_{\theta c_{\mathrm{II}}}=\left.\sum_{v=0}^{4} \sum_{m=1}^{\infty} B_{\theta c_{\mathrm{I} v}} \sigma_{c}\left(\mathrm{I}_{v}\right)\right|_{r=R_{r o}}
\end{aligned}
$$

where the correlation functions $\kappa_{c}$ and $\sigma_{c}$ are given in the Appendix. In a similar manner, the normal magnetic field between the airgap, permanent magnets and stator slots should be continuous and using modal analysis this gives

$$
\begin{aligned}
& B_{r s_{\mathrm{III} v}}=\left.\sum_{n=1}^{\infty}\left(B_{r s_{\mathrm{II}}} \varepsilon_{s}\left(\mathrm{III}_{v}\right)+B_{r c_{\mathrm{II}}} \varepsilon_{c}\left(\mathrm{III}_{v}\right)\right)\right|_{r=R_{s i}} \\
& B_{r s_{\mathrm{IV} v}}=\left.\sum_{n=1}^{\infty}\left(B_{r s_{\mathrm{II}}} \varepsilon_{s}\left(\mathrm{IV}_{v}\right)+B_{r c_{\mathrm{II}}} \varepsilon_{c}\left(\mathrm{IV}_{v}\right)\right)\right|_{r=R_{s i}} .
\end{aligned}
$$

The tangential magnetic field between the airgap, permanent magnets and stator slots should be continuous and zero at the stator teeth giving

$$
\begin{aligned}
& B_{\theta s_{\mathrm{II}}}=\sum_{v=0}^{5} {\left[\sum_{m=1}^{\infty}\left[\frac{B_{\theta s_{\mathrm{III} v}}}{\mu_{r}} \kappa_{s}\left(\mathrm{III}_{v}\right)+B_{\theta s_{\mathrm{IV} v}} \kappa_{s}\left(\mathrm{IV}_{v}\right)\right]\right.} \\
&\left.+\left(B_{0_{\mathrm{III} v}}-B_{\mathrm{rem}}\right) \kappa_{0}\left(\mathrm{III}_{v}\right)+B_{0_{\mathrm{IV} v}} \kappa_{0}\left(\mathrm{IV}_{v}\right)\right]\left.\right|_{r=R_{s i}} \\
& B_{\theta c_{\mathrm{II}}}=\sum_{v=0}^{5}\left[\sum_{m=1}^{\infty}\left[\frac{B_{\theta s_{\mathrm{III} v}}}{\mu_{r}} \sigma_{s}\left(\mathrm{III}_{v}\right)+B_{\theta s_{\mathrm{IV} v}} \sigma_{s}\left(\mathrm{IV}_{v}\right)\right]\right. \\
&\left.+\left(B_{0_{\mathrm{III} v}}-B_{\mathrm{rem}}\right) \sigma_{0}\left(\mathrm{III}_{v}\right)+B_{0_{\mathrm{IV} v}} \sigma_{0}\left(\mathrm{IV}_{v}\right)\right]\left.\right|_{r=R_{s i}}
\end{aligned}
$$

where the correlation functions $\kappa_{s}, \sigma_{s}, \kappa_{0}$, and $\sigma_{0}$ are given in the Appendix. The normal magnetic field between the surrounding air region and permanent magnets should be continuous

$$
B_{r s_{\mathrm{III} v}}=\left.\sum_{n=1}^{\infty}\left(B_{r s_{\mathrm{V}}} \varepsilon_{s}\left(\mathrm{III}_{v}\right)+B_{r c_{\mathrm{V}}} \varepsilon_{c}\left(\mathrm{III}_{v}\right)\right)\right|_{r=R_{s o}} .
$$

Finally, the tangential magnetic field between the surrounding air region and permanent magnets should be continuous and zero at the stator back iron giving

$$
\begin{aligned}
B_{\theta s_{\mathrm{V}}}=\sum_{v=0}^{5} & {\left[\sum_{m=1}^{\infty} \frac{B_{\theta s_{\mathrm{III} v}}}{\mu_{r}} \kappa_{s}\left(\mathrm{III}_{v}\right)\right.} \\
& \left.+\left(B_{0_{\mathrm{III} v}}-B_{\mathrm{rem}}\right) \kappa_{0}\left(\mathrm{III}_{v}\right)\right]\left.\right|_{r=R_{s i}} \\
B_{\theta c_{\mathrm{V}}}=\sum_{v=0}^{5} & {\left[\sum_{m=1}^{\infty} \frac{B_{\theta s_{\mathrm{III} v}}}{\mu_{r}} \sigma_{s}\left(\mathrm{III}_{v}\right)\right.} \\
& \left.+\left(B_{0_{\mathrm{III} v}}-B_{\mathrm{rem}}\right) \sigma_{0}\left(\mathrm{III}_{v}\right)\right]\left.\right|_{r=R_{s i}} .
\end{aligned}
$$

The aforementioned boundary conditions solve the set of unknown variables for the flux density expressions. However additional boundary conditions are necessary to solve the unknown coefficients $A_{0_{\text {III }}}$ of region III. These can be obtained from setting the divergence of the magnetic flux density around the stator segment (see Fig. 3) to zero. These $6(v=0 \ldots 5)$ equations can be written as

$$
\begin{aligned}
& \left.\int_{\Delta_{\mathrm{III} v}+\tau_{m}}^{\Delta_{\mathrm{III}(v+1)}} B_{r_{\mathrm{V}}} r d \theta\right|_{r=R_{s o}}-\left.\int_{\Delta_{\mathrm{III} v}+\tau_{m}}^{\Delta_{\mathrm{III}(v+1)}} B_{r_{\mathrm{II}}} r d \theta\right|_{r=R_{s i}}+ \\
& \left.\int_{R_{s i}}^{R_{s o}} B_{\theta_{\mathrm{III}(v+1)}} d r\right|_{\theta=\Delta_{\mathrm{III}(v+1)}}-\left.\int_{R_{s i}}^{R_{s i}} B_{\theta_{\mathrm{III} v}} d r\right|_{\theta=\Delta_{\mathrm{III} v}+\tau_{m}}=0 .
\end{aligned}
$$

\section{Finite-Element Verification}

The magnetic field is calculated for the machine parameters given in Table I and verified with 2-D linear finite element anal- 
TABLE I

PARAMETERS OF THE FSPM

\begin{tabular}{|c|c|c|}
\hline Parameter & Value & Description \\
\hline$R_{r i}$ & $30.75 \mathrm{~mm}$ & Inner radius of the rotor teeth \\
\hline$R_{r o}$ & $40.75 \mathrm{~mm}$ & Outer radius of the rotor teeth \\
\hline$R_{s i}$ & $41.25 \mathrm{~mm}$ & Inner radius of the stator \\
\hline$R_{c}$ & $70 \mathrm{~mm}$ & Outer radius of the coils \\
\hline$R_{s o}$ & $75 \mathrm{~mm}$ & Outer radius of the stator \\
\hline$B_{r e m}$ & $1.2 \mathrm{~T}$ & Remanent flux density PMs \\
\hline$\mu_{r}$ & 1.05 & Relative permeability of PMs \\
\hline$\tau_{t}$ & $2 \pi / N_{r}$ & Pitch of the rotor teeth \\
\hline$\tau_{s}$ & $2 \pi / N_{s}$ & Pitch of the stator segments \\
\hline$\tau_{m}=\tau_{\mathrm{III} v}$ & $\tau_{s} / 4$ & Width of the PMs \\
\hline$\tau_{\mathrm{c}}=\tau_{\mathrm{IV} v}$ & $\tau_{s} / 4$ & Width of the coil region \\
\hline$\tau_{r}=\tau_{\mathrm{I} v}$ & $\tau_{t}-\tau_{m}$ & Width of the rotor slot openings \\
\hline$L$ & $0.1 \mathrm{~m}$ & Active length \\
\hline$N I$ & 100 & Amplitude of Amp ère turns per coil \\
\hline \multicolumn{2}{|c}{} \\
\hline \multicolumn{2}{|c}{}
\end{tabular}

ysis. The solution in the centre of the airgap is shown in Fig. 4 where excellent agreement is obtained. A mesh-free description of the flux density waveform is obtained, giving a better accuracy for the linear case than the coarse solution of the MEC model, which is limited by the number of included permeances. Furthermore, for the MEC model, only the radial component of the flux density is obtained. However, it can be observed that very high flux density levels upto $6 \mathrm{~T}$ are obtained. This indicates that the soft-magnetic material will be saturated and in general the flux density in the airgap will be lower as well as the generated output torque. Therefore, this modeling technique needs an additional model in the form of an hybrid model to account for this effect. The output torque can be calculated by means of integrating the Maxwell stress tensor over the rotor surface giving

$$
\begin{aligned}
T & =\left.\frac{L}{\mu_{0}} \int_{0}^{2 \pi} r^{2} B_{r_{\mathrm{II}}} B_{\theta_{\mathrm{II}}} d \theta\right|_{r=R_{r o}}, \\
& =\frac{2 \pi L}{\mu_{0}} \sum_{n=1}^{\infty}\left(b_{n_{\mathrm{II}}} c_{n_{\mathrm{II}}}-a_{n_{\mathrm{II}}} d_{n_{\mathrm{II}}}\right) .
\end{aligned}
$$

The coils can be commutated in order to produce electromagnetic and reluctance torque. However, since the latter is relatively small [2], only the electromagnetic torque is considered in both the analytical and FE model. The FE verification is shown in Fig. 5 where a very good agreement is obtained. The small discrepancy is caused by the limitation in the number of harmonics that can be included.

\section{CONCLUSION}

An alternative analytical technique for modeling an FSPM machine is discussed, based on Fourier analysis, where the periodic geometry is divided into regions. The Maxwell equations are solved in terms of the magnetic vector potential for the resulting boundary value problem. The output torque can be calculated analytically by means of the Maxwell stress tensor method. The results are verified with 2-D linear FEA and very good agreement is obtained. The model accuracy is significantly less dependent on parameter variation than the MEC method. Al-
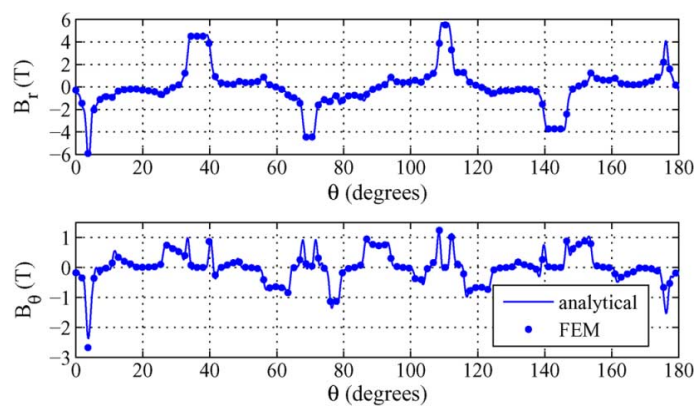

Fig. 4. Radial and tangential components of the flux density distribution at centre of the airgap.

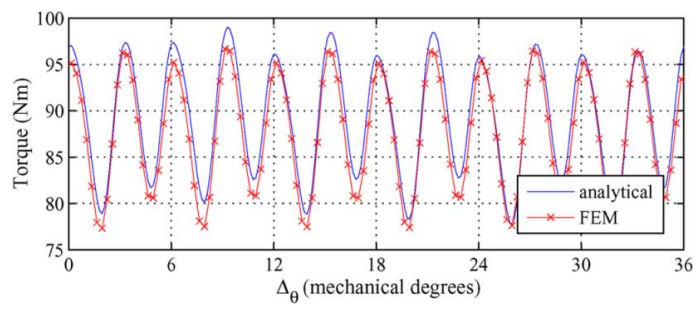

Fig. 5. Electromagnetic torque profile.

though the nonlinear behavior cannot be included, this model is still valuable in combination with the FE or MEC method in a space-mapping or hybrid design algorithm.

\section{APPENDIX}

$$
\begin{aligned}
\varepsilon_{s}(k) & =\frac{4 m n^{2}\left[\sin \left(2 n \Delta_{k}\right)-(-1)^{m} \sin \left(2 n\left(\Delta_{k}+\tau_{k}\right)\right)\right]}{\pi\left(4 m^{2} n^{2}-n^{2} \tau_{k}^{2}\right)} \\
\varepsilon_{c}(k) & =\frac{4 m n^{2}\left[\cos \left(2 n \Delta_{k}\right)-(-1)^{m} \cos \left(2 n\left(\Delta_{k}+\tau_{k}\right)\right)\right]}{\pi\left(4 m^{2} n^{2}-n^{2} \tau_{k}^{2}\right)} \\
\kappa_{s}(k) & =\frac{2 m n \tau_{k}\left[\sin \left(2 n \Delta_{k}\right)-(-1)^{m} \sin \left(2 n\left(\Delta_{k}+\tau_{k}\right)\right)\right]}{\pi\left(4 m^{2} n^{2}-n^{2} \tau_{k}^{2}\right)} \\
\kappa_{0}(k) & =\frac{\left[\cos \left(2 n \Delta_{k}\right)-\cos \left(2 n\left(\Delta_{k}+\tau_{k}\right)\right)\right]}{n \pi} \\
\sigma_{s}(k) & =\frac{2 m n \tau_{k}\left[\cos \left(2 n \Delta_{k}\right)-(-1)^{m} \cos \left(2 n\left(\Delta_{k}+\tau_{k}\right)\right)\right]}{\pi\left(4 m^{2} n^{2}-n^{2} \tau_{k}^{2}\right)} \\
\sigma_{0}(k) & =\frac{-\left[\sin \left(2 n \Delta_{k}\right)-\sin \left(2 n\left(\Delta_{k}+\tau_{k}\right)\right)\right]}{n \pi} .
\end{aligned}
$$

\section{REFERENCES}

[1] J. Shen, Y. Wang, and C. Wang, in Proc. Ecologic Veh. Renewable Energies, 2009, pp. 1-8.

[2] Z. Zhu, Y. Pang, D. Howe, S. Iwasaki, R. Deodhar, and A. Pride, IEEE Trans. Magn., vol. 41, no. 11, pp. 4277-4287, Nov. 2005.

[3] A. Thomas, Z. Zhu, G. Jewell, and D. Howe, in Proc. ICEMS, Oct. 2008, pp. 2986-2991.

[4] Z. Zhu, D. Howe, E. Bolte, and B. Ackermann, IEEE Trans. Magn., vol. 29, no. 1, pp. 124-135, Jan. 1993.

[5] B. L. J. Gysen, K. J. Meessen, J. J. H. Paulides, and E. A. Lomonova, IEEE Trans. Magn., vol. 46, no. 1, pp. 39-52, Jan. 2010.

[6] L. Encica, J. J. H. Paulides, and E. A. Lomonova, COMPEL: Int. J. for Comput. Math. Elect. Electron. Eng., vol. 28, no. 5, pp. 1216-1226, 2009. 